\title{
Es bleibt spannend
}

Liebe Leserin, lieber Leser,

120 Jahre Automobilgeschichte begleiten zu können, ist ein Privileg für eine technische Fachzeitschrift. Die ATZ hat in dieser Zeit viele bahnbrechende und auch weniger relevante Entwicklungen publiziert und verortet. In der Rückschau fällt auf, dass so manches vor Jahrzehnten schon da war, dann aber wieder in der Versenkung verschwand: Elektrofahrzeuge sind ein gutes Beispiel hierfür. Bis Anfang der 1920er-Jahre waren sie ein fester Bestandteil im Straßenbild, und auch in den 1950er-Jahren gab es interessante Entwicklungen. Danach war viel Stillstand, erst seit ein paar Jahren nimmt die E-Mobilität wieder Fahrt auf. Andere Technologien, wie etwa die Hinterachslenkung bei Pkw, haben sich bis heute nicht durchgesetzt, auch wenn es immer wieder vielversprechende Ansätze dazu gab und gibt.

Dieses Sonderheft zum 120. Geburtstag der ATZ präsentiert natürlich auch einen
Rückblick auf zwölf Jahrzehnte Automobilentwicklung. Im Kern aber wagt es einen Ausblick auf die kommenden Jahre, die durch großen Wandel geprägt sein dürften. E-Mobilität, die notwendige Lösung der Verkehrsprobleme in der zunehmenden Zahl von Megastädten, die Überalterung vieler Gesellschaften sowie ein teilweise grundsätzlich anderes Mobilitätsverhalten der jungen Kundengeneration werden die Fortbewegung vielerorts grundsätzlich verändern. Die Frage, wie Mobilitäts- beziehungsweise Transportlösungen effizient und kundenorientiert abgebildet werden können und was dies für OEMs und Zulieferer bedeutet, ist eine der Kernaufgaben der Automobilindustrie heute. Diese spannende Entwicklung wird uns die kommenden Jahre und Jahrzehnte beschäftigen. Die Redaktion der ATZ treibt dabei dieselbe Faszination für Fahrzeugtechnik an wie Sie, die Leserinnen und Leser.

Wir wünschen Ihnen viel Spaß bei der Lektüre von „120 Jahre ATZ“.

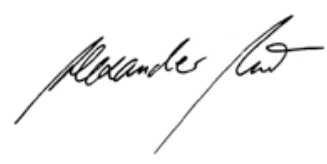

Dr. Alexander Heintzel Chefredakteur

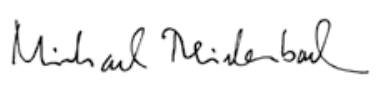

Dipl.-Ing. Michael Reichenbach Stellvertretender Chefredakteur

\section{Interieur 40}

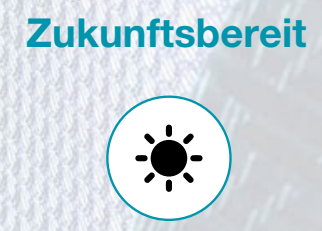

Innenraumlicht $\mathbf{2 . 0}$ individuelle Lichtszenarien als zentrales Element für Wohlbefinden



Funktionsintegration Integration flexibler Systeme und smarter Oberflächen



Autonomous Ready

drive, work \& relax: mobiler Ort für Arbeit und Entspannung

Neugierig? future@draexImaier.com 